\title{
Spirometry: an essential tool for screening, case-finding, and diagnosis of COPD
}

See linked articles by Thorn et al. on pg 159 and

Abramson et al. on pg 167

\section{Erika J Sims ${ }^{\mathrm{a}, \mathrm{b}}$, *David Price ${ }^{\mathrm{b}, \mathrm{c}}$}

a Norwich Medical School, Faculty of Health, University of East Anglia, UK

b Research in Real Life Ltd, Oakington, Cambridge, UK

c Centre of Academic Primary Care, University of Aberdeen, UK

*Correspondence: Professor David Price, Centre of Academic Primary Care, University of Aberdeen, Foresterhill Health Centre, Westburn Rd, Aberdeen, Scotland, AB25 2AY, UK

Tel: +44 (0)1224 554588 Fax: +44 (0)1224 840683

E-mail: david@respiratoryresearch.org

The Global Alliance against Chronic Respiratory Diseases estimates that there are 210 million cases of chronic obstructive pulmonary disease (COPD) globally. ${ }^{1}$ The Global Initiative for Chronic Obstructive Lung Disease (GOLD) guidelines ${ }^{2}$ and the International Primary Care Respiratory Group (IPCRG) ${ }^{3}$ have identified that many patients are diagnosed late, and consequently that case-finding strategies should be employed. Rather than just using case-finding as a means of diagnosing patients, the strategy proposed by the IPCRG involves reviewing 'at risk' populations - i.e. current and exsmokers aged over 35 years of age - and using spirometry or questionnaires or both to identify 'likely COPD' patients who then require high quality diagnostic standard spirometry., ${ }^{4.5}$ this issue of the PCRJ there are two papers which shed further light on aspects of this diagnostic process. In the first paper, Thorn and colleagues report on the copd- 6 - a simple hand-held microspirometer device (Vitalograph, Ireland) that measures $\mathrm{FEV}_{1} / \mathrm{FEV}_{6}$ - and its usefulness and cost-effectiveness in providing pre-standard spirometry for COPD case-finding. ${ }^{6}$ In the second, Abramson et al. report a mixed methods study on the accuracy of asthma and COPD diagnosis in Australian primary care.

There are considered perspectives available from both proponents and opponents to the concept of COPD case-finding in primary care - as previously debated and then summarised recently in this journal. ${ }^{8}$ Furthermore, there is no consensus as to which casefinding method is best - microspirometry versus standard spirometry - and whether these should be performed either pre- or postbronchodilator ${ }^{8-10}$ and with or without questionnaire screening., ${ }^{411}$ Thorn and colleagues ${ }^{6}$ report that a pre-bronchodilator $\mathrm{FEV}_{1} / \mathrm{FEV}_{6}$ ratio $<0.73$, measured using the hand-held copd- 6 , could be used as a case-finding test prior to referral for diagnostic spirometry in order to confirm or refute a diagnosis of COPD. Using diagnostic postbronchodilator spirometry, they then demonstrated a COPD prevalence of $25.2 \%$ in a patient population of 305 current and exsmokers (at least 15 pack years) aged 45 to 85 years who had been identified from 21 urban and rural primary health centres in Sweden.
Using the $\mathrm{FEV}_{1} / \mathrm{FEV}_{6}<0.73$ criterion, compared to standard spirometry, the sensitivity and specificity of the copd- 6 test was $79.2 \%$ and $80.3 \%$, respectively. In terms of negative and positive predictive values the copd- 6 had an accuracy of negatively predicting COPD (i.e. excluding the disease) $91.9 \%$ of the time, but only positively identifying COPD $57 \%$ of the time. These results are similar to those reported recently by Frith ${ }^{9}$ and Sichletidis ${ }^{10}$ using the Piko- 6 device. However, there is no agreement between all these articles as to the appropriate cut-off for $\mathrm{FEV}_{1} / \mathrm{FEV}_{6}$ or whether $\mathrm{FEV}_{1} / \mathrm{FEV}_{6}$ should be combined with a questionnaire (see Table 1 ).

Kotz and van Schayck, in an accompanying editorial to the Frith ${ }^{9}$ and Sichletidis ${ }^{10}$ articles, eloquently describe the necessity for higher sensitivity at the risk of losing specificity in order to minimise falsenegatives. In other words, maximising the chances of positively identifying COPD means that more patients would have to be referred for confirmatory diagnostic spirometry, arguably unnecessarily. All three microspirometry studies $s^{6,9,10}$ demonstrate a high negative predictive value - i.e. they predict with at least $90 \%$ accuracy that the patient does not have COPD. As the severity and symptom profiles of the patients missed by the screening strategies are not reported, whether these patients had mild disease or were asymptomatic is unknown.

Case-finding questionnaires could be utilised instead of microspirometry. As reviewed by Soriano and colleagues, ${ }^{4}$ a casefinding questionnaire offers greater convenience than microspirometry, although questionnaires based on symptoms alone may miss some asymptomatic patients. Price et al. ${ }^{12}$ reported that a case-finding questionnaire (IPAG) based on variables associated with an increased or decreased risk of having COPD - including age, body mass index, allergies, hospitalisations and symptoms - had an 89 $93 \%$ accuracy of negatively predicting COPD depending upon the

\section{Table 1. Sensitivity and specificity of $\mathrm{FEV}_{\mathbf{1}} / \mathrm{FEV}_{\mathbf{6}}$ at} cut-offs recommended by authors

\begin{tabular}{lllll} 
& Thorn $^{6}$ & Frith $^{9}$ & Sichletidis \\
\hline Device & copd-6 & Piko-6 & Piko-6 & $\begin{array}{l}\text { Piko-6 \& } \\
\text { IPAG }\end{array}$ \\
\hline FEV $1 /$ FEV 6 cut-off* & $<0.73$ & $<0.75$ & $<0.7$ & $<0.7$ \\
Sensitivity & $79 \%$ & $81 \%$ & $80 \%$ & $74 \%$ \\
Specificity & $80 \%$ & $71 \%$ & $94 \%$ & $97 \%$ \\
1-SN (false-negative) & $21 \%$ & $19 \%$ & $20 \%$ & $26 \%$ \\
1-SP false-positive) & $20 \%$ & $29 \%$ & $6 \%$ & $3 \%$ \\
Positive Predictive Value & $57 \%$ & $52 \%$ & $64 \%$ & $71 \%$ \\
Negative Predictive Value & $92 \%$ & $91 \%$ & $98 \%$ & $97 \%$ \\
\hline \multirow{2}{*}{${ }^{*}$ Cut-off recommended by authors. } & & &
\end{tabular}


score cut-off used. Combining spirometric and questionnaire approaches might improve the positive predictive value of the casefinding approach. Although Sichletidis et al. ${ }^{10}$ reported that combining the IPAG questionnaire and PiKo-6 flow meter was associated with a small improvement in the positive predictive value compared to the PiKo-6 flow meter alone, perhaps the choice of tool(s) used - microspirometry and/or questionnaire - should be dependent on what is most appropriate for the patient. Microspirometry (with or without questionnaire) could be used during opportunistic face-to-face consultations (analogous to the measurement of blood pressure in the consulting room), while questionnaires - sent by post or email - could be used as a means of identifying patients who wouldn't normally visit the primary care health centre.

If case-finding using $\mathrm{FEV}_{1} / \mathrm{FEV}_{6}$ were to be implemented, should it be performed pre- or post-bronchodilator? Indeed, while Frith ${ }^{9}$ and Thorn $^{6}$ utilised pre-bronchodilator measurements, Sichletidis ${ }^{10}$ advocated post-bronchodilator measurements. So which provides most utility - pre-bronchodilation or post-bronchodilation when using microspirometry? Thorn reported that pre-bronchodilator $\mathrm{FEV}_{1}$ measured using the copd- 6 was on average $0.18 \mathrm{~L}$ lower than the post-bronchodilator $\mathrm{FEV}_{1}$ recorded during standard spirometry, suggesting that as a case-finding measurement pre-bronchodilator values may be acceptable. Conducting post-bronchodilator casefinding would also increase the training required, the need for clinical supervision, and the cost. ${ }^{6}$ This would potentially reduce the utility of the test. Indeed, since the UK National Institute of Health and Clinical Excellence (NICE) guideline for COPD ${ }^{13}$ advocates opportunistic case-finding conducted in 'at risk' populations, the case-finding test would need to be available for use at general practice facilities, smoking cessations clinics or local pharmacies. Comparative studies evaluating pre-bronchodilator and postbronchodilator microspirometry to confirm the validity of prebronchodilator measurements are required.

However, we need to ensure that this debate on the tools required for primary care COPD case-finding has real relevance to 'grass-roots' general practice. Abramson and colleagues report that COPD is substantially under-diagnosed in primary care in Australia. Guidelines recommend that a diagnosis of COPD should be made on the basis of spirometry, symptoms and smoking history.,211 Yet, in a retrospective review of 278 new doctor diagnoses of asthma and COPD made during a 12 -month period, over $28 \%$ of the diagnoses were made without spirometry. Of the 199 patients with baseline diagnostic spirometry, evidence of post-bronchodilator airflow limitation consistent with COPD was found in 91 patients, of whom $51(56 \%)$ had a doctor diagnosis of asthma alone. In qualitative interviews with the participating general practitioners (GPS), the authors report that cost, both in terms of finance and staff time, was the principal driver for not conducting spirometry. This is an important insight, and one which needs to be considered whilst debating the utility of various case-finding strategies for COPD in primary care.

Initiation of therapy in COPD has been shown to be more effective at earlier rather than later stages in the disease progression. ${ }^{14,15}$ Case-finding strategies are essential if patients are to be identified in the early stages of the disease. Spirometry is an essential tool in the armoury of the GP for differentiating COPD from asthma. As treatments for COPD and asthma are diverging due to substantial improvements in our understanding of the pathogenesis of both diseases, the correct diagnosis is imperative in order to maximise the long-term outcome for the patient.

Conflicts of interest DP has consultant arrangements with Almirral, Astra Zeneca, Boehringer Ingelheim, Chiesi, GlaxoSmithKline, Merck, Mundipharma, Medapharma, Novartis, Napp, Nycomed, Pfizer, Sandoz and Teva. He or his research team have received grants and support for research in respiratory disease from the following organisations in the last 5 years: UK National Health Service, Aerocrine, AstraZeneca, Boehringer Ingelheim, Chiesi, GlaxoSmithKline, Merck, Mundipharma, Novartis, Nycomed, Orion, Pfizer, and Teva.

He has spoken for: Almirral, AstraZeneca, Activaero, Boehringer Ingelheim, Chiesi, Cipla, GlaxoSmithKline, Kyorin, Merck, Mundipharma, Pfizer and Teva.

He has shares in AKL Ltd which produces phytopharmaceuticals. He is the sole owner of Research in Real Life Ltd.

EJS declares that she has no conflicts of interest in relation to this article.

Commissioned article; not externally peer-reviewed; accepted 12th May 2012; online 18th May 2012

(c) 2012 Primary Care Respiratory Society UK. All rights reserved http://dx.doi.org/10.4104/pcrj.2012.00046

Prim Care Respir J 2012;21(2):128-30

\section{References}

1. Global surveillance, prevention and control of chronic respiratory diseases: a comprehensive approach Geneva: World, Health Organisation2007 25 August 2007.

2. Global Initiative for Chronic Obstructive Lung Disease Global Strategy for The Diagnosis, Management and Prevention of Chronic Obstructive Pulmonary Disease (Updated 2009): Medical Communications Resources, Inc; 2009.

3. Levy ML, Fletcher M, Price DB, Hausen T, Halbert RJ, Yawn BP. International Primary Care Respiratory Group (IPCRG) Guidelines: diagnosis of respiratory diseases in primary care. Prim Care Respir J 2006;15(1):20-34 http://dx.doi.org/ 10.1016/j.pcrj.2005.10.004

4. Soriano JB, Zielinski J, Price D. Screening for and early detection of chronic obstructive pulmonary disease. Lancet 2009;374(9691):721-32. http://dx.doi.org/10.1016/ S0140-6736(09)61290-3

5. Price $D$, Crockett $A$, Arne $M$, et al. Spirometry in primary care case-identification, diagnosis and management of COPD. Prim Care Respir J 2009;18(3):216-23. http://dx.doi.org/10.4104/pcrj.2009.00055

6. Thorn J, Tilling B, Lisspers K, Jorgensen L, Stenling A, Stratelis G. Improved prediction of COPD in at-risk patients using lung function pre-screening in primary care: a reallife study and cost-effectiveness analysis. Prim Care Respir J 2012;21(2):159-66. http://dx.doi.org/10.4104/pcrj.2011.00104

7. Abramson MJ, Schattner RL, Sulaiman ND, Del Colle EA, Aroni R, Thien F. Accuracy of asthma and COPD diagnosis in Australian general practice: a mixed methods study. Prim Care Respir J 2012;21(2):167-73.

http://dx.doi.org/10.4104/ pcrj.2011.00103

8. Kotz D, van Schayck OC. Interpreting the diagnostic accuracy of tools for early detection of COPD. [Editorial] Prim Care Respir J 2011;20(2):113-15. http://dx.doi.org/10.4104/pcrj.2011.00050

9. Frith P, Crockett A, Beilby J, et al. Simplified COPD screening: validation of the PiKo6(R) in primary care. Prim Care Respir J 2011;20(2):190-8. http://dx.doi.org/10.4104/pcrj.2011.00040

10. Sichletidis $L$, Spyratos $D$, Papaioannou $M$, et al. A combination of the IPAG questionnaire and PiKo-6(R) flow meter is a valuable screening tool for COPD in the primary care setting. Prim Care Respir J 2011;20(2):184-9. http://dx.doi.org/10.4104/pcrj.2011.00038

11. Price D, Freeman D, Cleland J, Kaplan A, Cerasoli F. Earlier diagnosis and earlier treatment of COPD in primary care. Prim Care Respir J 2011;20(1):15-22. 
http://dx.doi.org/10.4104/pcrj.2010.00060

12. Price DB, Tinkelman DG, Nordyke RJ, Isonaka S, Halbert RJ. Scoring system and clinical application of COPD diagnostic questionnaires. Chest 2006;129(6):1531-9. http://dx.doi.org/10.1378/chest.129.6.1531

13. Excellence NNIfHaC. Chronic obstructive pulmonary disease: management of chronic obstructive pulmonary disease in adults in primary and secondary care. National Clinical Guideline Centre - Acute and Chronic Conditions; 2010.
14. Decramer M, Celli B, Kesten S, Lystig T, Mehra S, Tashkin DP. Effect of tiotropium on outcomes in patients with moderate chronic obstructive pulmonary disease (UPLIFT): a prespecified subgroup analysis of a randomised controlled trial. Lancet 2009;374(9696):1171-8. http://dx.doi.org/10.1016/S0140-6736(09)61298-8

15. Jenkins $C R$, Jones PW, Calverley PM, et al. Efficacy of salmeterol/fluticasone propionate by GOLD stage of chronic obstructive pulmonary disease: analysis from the randomised, placebo-controlled TORCH study. Respir Res 2009;10:59.

\section{Acute rhinosinusitis - does quality of life explain continued rates of antibiotic overusage?}

\section{See linked article by Stjärne et al. on pg 174}

\section{*Sam Friedlander ${ }^{\mathrm{a}}$}

a Assistant Clinical Professor, CASE, Department of Allergy/Immunology and Sleep Medicine, University Hospitals of Cleveland, Cleveland, Ohio, USA

*Correspondence: Professor Sam Friedlander, Department of Allergy/Immunology and Sleep Medicine, CASE, University Hospitals of Cleveland, Cleveland, Ohio, USA Tel: 440-248-1630 Fax: 440-349-8160

E-mail: Samuel.Friedlander@uhhospitals.org

Quality of life (QoL) measurement is central to quantifying the burden of illness over a range of disease states. Particularly for diseases that infrequently result in mortality or hospitalisation, QoL indices can highlight the important impact of a condition. ${ }^{1}$ One such illness is acute rhinosinusitis, one of the most common reasons for which patients seek out medical attention. Approximately $6-15 \%$ of the population is affected by acute rhinosinusitis and it is estimated that 2-5 episodes of common viral colds occur per year in adults. ${ }^{2}$ In school-aged children the numbers are even higher, with 7-10 occurrences per year. The resultant healthcare utilisation worldwide is great, comprising $3-10 \%$ of all physician visits. ${ }^{3.4}$ As a result, there is a pressing research need to study acute rhinosinusitis and its impact on QoL and economic cost, its co-morbid risk factors, and the prevention of harm from the overuse of antibiotics. ${ }^{5}$

Primary care providers have the major responsibility for managing this condition, and thus it is appropriate to study acute rhinosinusitis in a primary care setting. In this issue of the Primary Care Respiratory Journal, Stjärne and colleagues ${ }^{6}$ report on the high costs and health-related QoL in acute rhinosinusitis in a Swedish primary care setting. Using a prospective, observational study design at 11 sites, QoL and cost analyses in adults with acute rhinosinusitis were assessed. Subjects were evaluated by the rhinosinusitis-specific Major Symptoms Score and overall QoL measure EQ-5D $\mathrm{D}^{\mathrm{TM}}$ at days 0 and 15. Those with clinically suspected fulminant bacterial rhinosinusitis (e.g. fever, worsening of symptoms after initial improvement or "double sickening," persistent unilateral facial or tooth pain) were excluded. A high rate of subjects reported symptoms detrimental to QoL. At the initial visit, $88 \%$ of participants reported pain/discomfort and $43 \%$ had problems with usual activities, although only $11 \%$ reported extreme pain. The vast majority of subjects - $91 \%$ - improved their symptom scores by at least $30 \%$ between days 0 to 15 .

In addition to patients' decreased QoL, the paper by Stjärne and colleagues informs us of the high economic cost to society of acute rhinosinusitis, mainly related to indirect costs. Interestingly, they found a wide variation in cost, from 1,728 to 54,357 SEK (194 to $6,111 €)$ with a mean cost of 10,260 SEK $(1,102 €)$. Of this, 7,781 SEK was due to indirect costs from a fall in productivity related to employment status and work absence.

The authors are to be commended for conducting a high-quality, multicentre study of acute rhinosinusitis in a primary care setting. They have added to the limited evidence base on acute rhinosinusitis and its effects on disease-specific symptom scores and QoL. Further, direct and indirect costs of this disease have not been well-studied before, and have never been evaluated in Scandinavia.

Allergy is a risk factor for acute rhinosinusitis ${ }^{7}$ and a quarter of the subjects in this paper ${ }^{6}$ report having seasonal allergies. This highlights the importance of assessing for the role of allergies. There are multiple pathophysiological explanations for the connection between allergy and rhinosinusitis. ${ }^{2}$ This includes impaired ciliary function in allergic rhinitis ${ }^{8}$ and elevated expression of ICAM -1, the receptor for rhinovirus. ${ }^{9}$ Also, numbers of plasmacytoid dendritic cells, important for combating viral infection, are decreased in asymptomatic patients with chronic nasal allergic inflammation. ${ }^{10}$

Another major concern is the global overuse of antibiotics for the treatment of acute rhinosinusitis, a mainly viral disease. ${ }^{11}$ This was largely borne out in this study by Stjärne and colleagues, ${ }^{6}$ since $60 \%$ were treated by their provider with antibiotics. Usually, the number of patients taking a medicine is less than those that were prescribed it. Ironically, although $60 \%$ were initially recommended by their doctor to take antibiotics, $69 \%$ actually reported using antibiotics. Not enough information is available to explain why antibiotics were recommended or used, although the high numbers suggest that overuse occurred. Potentially, subjects not initially prescribed antibiotics might have returned to the same or different medical provider to obtain them.

It is estimated that only $0.5-2 \%$ of viral colds result in bacterial rhinosinusitis, so it is disappointing that such high rates of antibiotics continue to be prescribed. ${ }^{12}$ Clinical practice guidelines recommend antibacterial treatment for persistent symptoms lasting more than 10 days or for patients with severe symptoms, in order to speed 